\title{
sciendo
}

Transport and Telecommunication, 2021, volume 22, no. 1, 67-86

Transport and Telecommunication Institute, Lomonosova 1, Riga, LV-1019, Latvia

DOI 10.2478/ttj-2021-0006

\section{INVENTORY ROUTING ANALYSIS FOR MARITIME LNG SUPPLY OF GERMAN PORTS}

\author{
Felix Prause ${ }^{1}$, Gunnar Prause ${ }^{2,3}$ \\ ${ }^{1}$ Berlin University of Technology, \\ Straße des 17. Juni 135, 10623 Berlin, Germany \\ ${ }^{2}$ Tallinn University of Technology, \\ Ehitajate tee 5, 19086 Tallinn, Estonia \\ ${ }^{3}$ Wismar University of Applied Sciences, \\ Philipp-Müller-Str. 14, 23966 Wismar, Germany \\ f.prause@campus.tu-berlin.de,gunnar.prause@taltech.ee
}

\begin{abstract}
After the implementation of Emission Control Areas (ECA) in Northern Europe in 2015, ship operators have to decide for new compliance methods. Among different abatement technologies, also the use of LNG as maritime fuel is one option. Hence, the number of LNG-fueled vessels plying in North Sea and Baltic Sea is growing, so ports have to cope with the increasing demand for LNG. Until now, German ports have been a little bit delayed in the installation of LNG infrastructure. Currently, a new LNGterminal at Brunsbüttel, the western entrance to the Kiel Canal, is under construction.

The distribution of LNG from the new LNG-hub to the other German ports can be modelled as an Inventory Routing Problem (IRP) that is usually solved by combinatorial optimization methods. This paper investigates the research question, how the distribution can be modeled as an IRP, which distribution mode is the most economic for the German ports and which modal mix for the LNG supply leads to the greenest distribution. The results of this paper are empirically validated by data that were collected in several EU-projects on sustainable supply chain management and green logistics.
\end{abstract}

Keywords: Inventory Routing Problem, LNG distribution, clean shipping, operations research

\section{Introduction}

The International Maritime Organization (IMO) and the European Parliament (EP) decided in 2005 and 2012 to establish Emission Control Areas (SECA) in Northern Europe comprising North Sea and Baltic Sea from 2015 on. The first step towards green shipping was the implementation of the SECA regulation in the Baltic Sea Region (BSR) in 2015 where operating ships, from 2015 on, must use fuel with a low sulphur content not exceeding $0.1 \%$. Next steps towards cleaner shipping are the NECA regulation for ECA that will be in force from 2021 and the global CAP that will limit the sulphur content in maritime fuel to $0.5 \%$ in all seas (Prause \& Olaniyi, 2019).

Before the implementation of ECA regulation, many studies highlighted the tentative negative impact of these environmental rules on the maritime industry. Consequently, the European Union approved in the frame of the BSR Interreg Programme the projects "EnviSuM - Environmental Impact of Low Emission Shipping Measurements and Modelling Strategies" and "GoLNG" to assess the technical efficiency and the socio-economic impacts of clean shipping solutions in the Baltic Sea Region (BSR). After more than three years of project activities, some of the published results of the socio-economic impacts of the regulation focused majorly on emission measurements, the efficiency of abatement technologies and economic impacts of SECA regulations on the maritime stakeholders (Atari et al., 2019; Olaniyi et al., 2018).

Nevertheless, no significant logistics issues for maritime sector were detected until now. One important reason for that was that most of the vessels that operate in the Baltic Sea now use low sulphur maritime fuel that was, since 2015, most of the time less expensive than the formerly used heavy fuel oil due to low oil prices. Latest research results on administrative burden, additional fuel costs and a real option-based evaluation of abatement technology investments also showed neglectable impact on the maritime industry. Hence, the SECA regulation have not met the maritime sceptics that were expected before 2014 (Atari et al., 2019; Prause \& Olaniyi, 2019).

One important change until 2015 was the increasing perception of LNG as an alternative maritime fuel that is compliant with SECA regulation and upcoming NECA regulation as well. The increasing 
number of LNG-fuelled vessels plying in North Sea and Baltic Sea forced the ports to cope with the growing LNG demand but the readiness of LNG supply for the maritime sector was not equally developed, especially in BSR (Olaniyi \& Gerlitz, 2019). Until now, German ports have been a little bit delayed in the installation of LNG infrastructure so that recently a new LNG-terminal at the Port of Brunsbüttel (Elbehafen), situated the western entrance to the Kiel Canal, will be the main entrance point for LNG into the German market with a terminal capacity of 5 billion $\mathrm{m} 3$. With the establishment of a new German LNG-hub, the distribution of the LNG between the LNG-hub and the other German ports moves into the focus representing a classical Inventory Routing Problem (Bertazzi et al., 2002, Dror et al., 1985).

By estimating the LNG-consumption of each German main port at the Baltic and the North Sea, three different models will be calculated and discussed that will meet the LNG demands of the considered German ports and that could be supplied by vessels, trucks and a mixture of both transport modes. The models will take under account the costs of each distribution channel as well as the related $\mathrm{CO} 2$ emissions. Surprisingly, it will turn out that currently the main costs of LNG distribution are caused by the storage of the LNG. The mathematical models are built and solved by Mixed Integer Programming (MIP) that is well known in business logistics (Pochet \& Wolsey, 2006).

This paper investigates different scenarios for the LNG-distribution from Elbehafen to the other German ports together with different modes of operation by comparing transport costs of vessels and trucks as well as the cost of LNG storage at the ports. The different scenarios will be further analyzed and discussed to determine the $\mathrm{CO} 2$ emissions that occur in each scenario, giving the reader a possibility to estimate the ecologically dimensions of the different distribution channels. Hence, the research discusses the research questions, how the LNG distribution among the German ports can be modeled as an IRP, which distribution mode is the most efficient and which modal mix is the greenest. The results of this paper are empirically validated by data that were collected in several EU-projects on sustainable supply chain management and green logistics. The research data are from desktop research and from primary data collected mainly in the EU-projects "EnviSuM" and "GoLNG" within the last two years.

\section{Literature Review}

The IRP is a topic that gained a lot of attention in recent years and which has been investigated in a great variety of applications. Surveys of papers and comparisons of algorithms can be found in (Bertazzi et al., 2002, Dror et al., 1985). The IRP is usually solved by combinatorial optimization methods, other formulations of the problem as a Markov decision process and a two-phase approach for the decomposition of the problem are the topics in (Campbell \& Savelsbergh, 2004; Kleywegt et al., 2000). Further, there is a lot of resent work on adapting and expanding the IRP to subjects like green logistics and perishable products (Cheng et al., 2016; Soysal et al., 2016). De et al., (2017) considered special cases in maritime logistics and for scenarios where network disruptions occurs, simultaneous pick-ups and deliveries have to be made or closed supply chain loops have to be investigated (van Anholt et al., 2016; Morales et al., 2018; Soysal, 2016).

The main idea of the IRP is to consider a fix length of each time-step, i.e., the amount of time that can at most be used to fulfill all deliveries in that time-step. Hence, consider a sequence of time-steps to figure out the best routes for supply such that the operation, transport and storage costs of the solution are as small as possible, using one distributing vehicle. The advantage of considering more time-steps in the model gives rise to solutions that use different routes in each time-step, such that some retailers do not have to be supplied every time-step, resulting in lower total cost of the whole model.

Normally there is a fixed storing-capacity given and the amount of the routed inventory that is stored in the fixed storage is accounted in the objective function of the minimization. In our case, we assume that there are no storing facilities at the ports; and consider the maximal amount of gas that can be stored at each port in the objective function of our MIP approach, such that the size of storage, with respect to the considered price for storing LNG, at each port is optimized as well. Hence, we obtain an optimal solution concerning the costs that also delivers the best corresponding size of the storages. Subsequently, the results will be compared to a model in which the gas is delivered by trucks and for which a MIP-formulation of a Vehicle Routing Problem (VRP) is used to determine the minimal total costs of the supply.

The VRP, like the IRP, has been research object for many scholars with a great variety of special cases and scenarios comprising green logistics and even electric vehicles (Braekers et al., 2016; Laporte, 1992; Bektaş et al., 2016; Hiermann et al., 2016). (Desrochers et al., 1992) give an insight view on scenarios where the supply has to be made in given time-windows, whereas (Lalla-Ruiz et al., 2016) 
investigated VRPs with more than one depot from which the customers can be supplied. Since VRPs are usually hard to solve in the case of many time-steps or a large number of customers, heuristics like TABU or simulated annealing approaches are widely used to solve the problem (Gendreau et al., 1994; Osman, 1993).

In the situation of German ports where the LNG distributing trucks are able to reach every port within one day, the optimization tasks can be solved on daily basis because the ports can be equipped with LNG-storages to buffer the daily demand. Consequently, it is possible to perform a preprocessing, in which all the demand of the ports, representing an integer value of full truckloads, is delivered, i.e. we only have to consider the demand in the VRP that is less than a truck load (LTL), i.e. in-between an empty and a full truckload. Then, we solve the VRP and obtain a solution that determines how many trucks are needed, and which route each truck has to use to satisfy the demand such that the total costs of this distribution model are minimal.

\section{Methodology}

The paper follows for the representation of underlying geographical data a graph-theoretical model with a set of vertices consisting important German ports. We consider besides the new LNG-hub Brunsbüttel (BRB) the four largest German North Sea ports Bremen/Bremerhaven (BRE), Cuxhaven (CUX), Hamburg (HAM) and Wilhelmshaven (WIL) as well as the four German Baltic Sea ports Kiel (KIE), Lübeck (LUE), Rostock (ROS) and Sassnitz (SAS). Based on these nine ports we construct a graph $\mathrm{G}=(\mathrm{V}, \mathrm{E})$, where the vertex set $\mathrm{V}$ is the set of the ports and $\mathrm{E}$ is the set of all possible edges representing the linkages between the ports. Since the Kiel Canal (NOK) connects the western and eastern German ports, the underlying graph consists of two complete graphs that are only connected by a single edge, starting and ending in Brunsbüttel. A tour containing the Baltic ports has to use the NOK-edge twice (Figure 1):

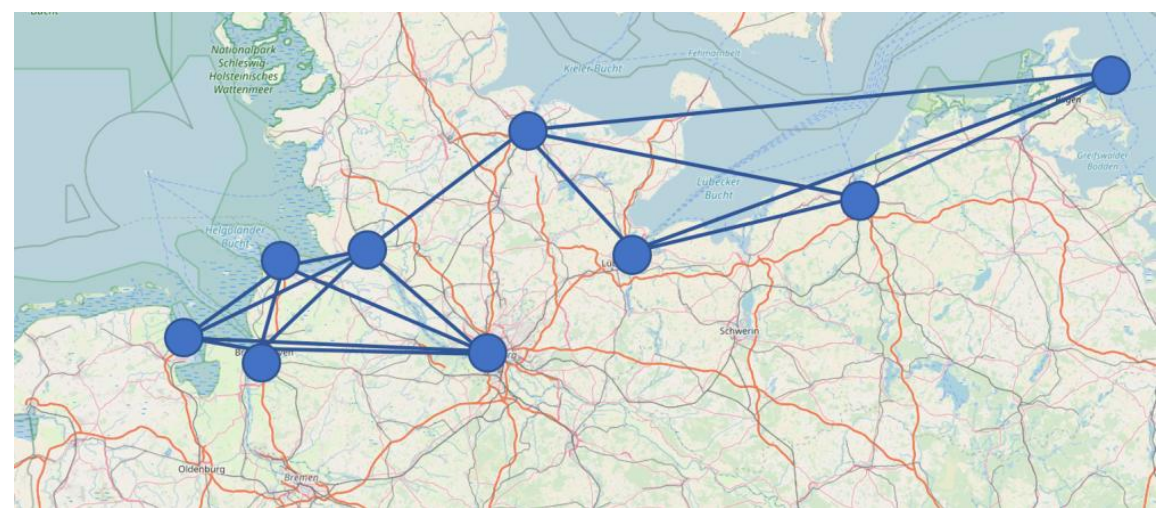

Figure 1. The transport graph of German main ports

The distances between the ports are determined by a sea-distance-matrix, i.e., we first consider LNG transport only between ports via vessels. Besides the sea-distances in one model also the roaddistances for a tentative truck transport of LNG between German ports are considered. For the calculation of the sea-distances as well as those for the road-distances, we use well-known internet sources (Seadistances 2019; OpenStreetMap 2020). Based on the distances via sea or road we use average CO2 emissions for each edge that are estimated by using emission tables for different transport modes depending on distance and cargo load provided by (Cefic 2011). The costs in our models represent full costs and all cost references are taken from internationally recognized studies of business logistics. Since we discuss different transport modes as well as several distribution technologies, we have to rely on a couple of studies covering the investigated topics.

The special structure of the graph $\mathrm{G}$ and the role of the Kiel Canal (NOK) requires for the modelling a small modification. We add an additional node for Kiel (KI2) to the vertex set V of the graph, i.e., there are two nodes representing Kiel, such that a tour through the Baltic ports starting at Brunsbüttel (BRB) is possible and we can apply the IRP model. The node KI2 has the same distances and edge-costs to all other Baltic ports as Kiel (KIE), i.e., an edge (KI2, BRB) is labeled with the same costs as (KIE, $\mathrm{BRB})$ and there exists an additional edge (KI2, KIE) with costs equal to zero and a demand of 0 tons per time-step. 
In the sequel, we will analyze and discuss three different models for LNG supply that are all extensions of the model of a Traveling-Salesman-Problem (TSP). The TSP model is applied to the graph having its start and end in Brunsbüttel in order to find the shortest tour through all given ports, what is exactly a Traveling-Salesman-Problem (TSP). The TSP model is considered as an Integer Program (IP) that leads according to Dantzig, Fulkerson and Johnson (Dantzig et al., 1954) to a set of equations that are describes in the following Table 1:

Table 1. The set of equations for the TSP program

$$
\begin{aligned}
& \min \sum_{(i, j) \in E} d_{i j} x_{i j} \\
& \text { s.t. } \quad \sum_{j \in V} x_{i j}=2 \quad \forall i \in V \\
& \sum_{i, j \in S, i \neq j} x_{i j} \leq|S|-1 \quad \forall S \subseteq V, S \neq \emptyset \\
& x_{i j} \in\{0,1\} \quad \forall(i, j) \in E
\end{aligned}
$$

Here $x_{i j}$ is a binary decision variable determining if the edge $(i, j)$ is included in the resulting tour or not and $d_{i j}$ is the length of the edge $(i, j)$.

Finally, the LNG demand of the German mains ports has to be estimated. There are several studies estimating the annual demand of LNG in ports. A realistic prognosis represents the LNG potential analysis of MEG (2017) so that we use this study to estimate the LNG-consumption of each German main port at the Baltic and the North Sea. Based on this estimation we develop, calculate and discuss three different models meeting the LNG demands of all considered German ports. The models take under account different transport modes for supply as well as the corresponding costs and $\mathrm{CO} 2$ emissions of each distribution channel. After the calculations, the main costs of the LNG distribution will be compared with the storage costs of LNG in the ports.

Since demand of LNG is given either in tons or in $\mathrm{m}^{3}$, every now and then it is necessary to convert volumes of LNG between $\mathrm{m}^{3}$ and tons. We will use in these situations the density factor $0.4681 \frac{t}{\mathrm{~m}^{3}}$ in accordance with the LNG Density Calculator (2019). In order to get an overview of the LNG demand in the German ports, we apply the results of the potential analysis of Merkel Energy (2017) that forecasts the LNG demand of the German North Sea ports for the year 2030. Based on this data, we calculate first the daily LNG demand by assuming an equal distribution. The missing values for the German Baltic ports we extrapolate by investigating the data of the AIS Marine Traffic for the Baltic Sea, which delivers the number of calls in German ports.

An analysis of the Marine Traffic data for the time between 22.12.2018 and 21.01.2019 yields the average number of daily calls by ships for all considered German ports (MarineTraffic 2019), which is integrated in the following table 1. Furthermore, we calculate the average demand of LNG per ship call within the German North Sea ports, which results in a median of 2.66 tons and a mean of 2.7 tons of LNG per call. This result we extrapolate to the German Baltic ports by forecasting conservatively the LNG demand since we use the median value of 2.66 tons of LNG per call. All calculations and results are visible in the following Table 2:

Table 2. LNG demand estimation for German ports (author's calculation)

\begin{tabular}{|l|c|c|c|c|c|}
\hline Port & $\begin{array}{c}\text { Annual demand } \\
\text { in 1000 tons }\end{array}$ & $\begin{array}{c}\text { Daily demand } \\
\text { in tons }\end{array}$ & $\begin{array}{c}\text { Average daily } \\
\text { Calls }\end{array}$ & $\begin{array}{c}\text { Daily demand } \\
\text { Per Call }\end{array}$ & $\begin{array}{c}\text { Estimated daily } \\
\text { demand }\end{array}$ \\
\hline BRB & 2.70 & 7.40 & 9.35 & 0.79 & 2.79 \\
\hline BRE & 63.90 & 175.07 & 62.66 & 0.97 & \\
\hline CUX & 8.10 & 22.19 & 22.87 & 7.66 & \\
\hline HAM & 74.40 & 203.84 & 76.55 & 6.29 & \\
\hline WIL & 17.40 & 47.67 & 7.58 & & 177.18 \\
\hline KIE & & & 66.61 & & 75.30 \\
\hline LUE & & & 28.29 & & 75.68 \\
\hline ROS & & & 28.45 & & 14.00 \\
\hline SAS & & & 5.26 & & $\mathbf{3 4 2 . 1 6}$ \\
\hline Sum & $\mathbf{1 6 6 . 5 0}$ & $\mathbf{4 5 6 . 1 7}$ & & & \\
\hline
\end{tabular}


For setting up the models, we further need a distance matrix for the shipping distances between the German ports that we express in nautical miles $(\mathrm{nm})$ and that we obtain by sea-distance calculator (Seadistances 2019). Further, the distance Brunsbüttel (BRB) - Kiel (KIE) is given by the length of the Kiel Canal (NOK), which has a sea distance of $54 \mathrm{~nm}$ and which can be travelled in about 10 hours. In addition to the sea distances, we also investigate the delivery of LNG by trucks, i.e., we additionally need the street-distances between the ports, which can be obtained by OpenStreetMap (2020 and that are visualized in Table 3:

Table 3. Distance matrix between German ports (author's calculation)

\begin{tabular}{|c|c|c|c|c|c|c|c|c|c|}
\hline $\mathrm{nm} / \mathrm{km}$ & BRB & BRE & CUX & HAM & WIL & KIE & LUE & ROS & SAS \\
\hline BRB & & $81 / 210$ & $16 / 205$ & $36 / 95$ & $78 / 270$ & $54 / 100$ & $151 / 135$ & $138 / 240$ & $198 / 375$ \\
\hline BRE & & & $65 / 45$ & $117 / 135$ & $63 / 80$ & $135 / 265$ & $232 / 250$ & $219 / 365$ & $279 / 490$ \\
\hline CUX & & & & $52 / 115$ & $62 / 110$ & $70 / 160$ & $167 / 285$ & $154 / 405$ & $214 / 525$ \\
\hline HAM & & & & & $114 / 205$ & $90 / 105$ & $187 / 90$ & $174 / 200$ & $234 / 325$ \\
\hline WIL & & & & & & $132 / 315$ & $229 / 300$ & $216 / 415$ & $276 / 540$ \\
\hline KIE & & & & & & $97 / 80$ & $84 / 215$ & $144 / 340$ \\
\hline LUE & & & & & & & & $60 / 140$ & $131 / 260$ \\
\hline ROS & & & & & & & & $88 / 120$ \\
\hline
\end{tabular}

Based on the distances we will calculate and discuss in the sequel three different inventory routing models for the LNG distribution among the German main ports. We will not only concentrate on LNG distribution by ships, but we also consider multimodal supply to the ports realized by vessels and trucks.

\section{Findings}

Based on the underlying data set, we will consider three different IPR models for the LNG distribution between the German main ports. The three approaches of the models differentiate between the distribution modes, i.e. we first consider the LNG-distribution by a vessel (model A), then the LNGdistribution by trucks (model B) and finally a mixed mode distribution (model C). We will evaluate and discuss the outcome of all investigated models in the sequel.

Our first model will be dedicated to the distribution of LNG by a single vessel and will be modeled in accordance with the Inventory Routing Problem (IRP) representing a combinatorial optimization model that naturally occurs in situations where we are confronted with internal deliveries, i.e., where the suppling and receiving facilities belong to the same company.

\subsection{Model A: LNG-distribution by a vessel}

The first approach to model the distribution of the LNG is based on deliveries via a vessel. Therefore, we follow (Archetti et al., 2007) and use their MIP formulation of the IRP. Since this model assumes that all deliveries can be done during one time-step, it is necessary to figure out and define how long this period is regarding our modelling, i.e., we have to find out what might be the longest tour a vessel can be confronted with. This task is equivalent to the determination of the shortest sea tour through all given cites in our underlying graph $\mathrm{G}=(\mathrm{V}, \mathrm{E})$, which is exactly the solution of a Traveling-SalesmanProblem (TSP).

As already mentioned, we apply the TSP model for both subgraphs as an Integer Program (IP), according to (Dantzig, Fulkerson and Johnson 1954) and using the SCIP Optimization Suite 6.0 (Gleixner et al., 2018), we obtain the following tours:
a. North Sea ports:
b. Baltic Sea ports:
c. Overall tour:

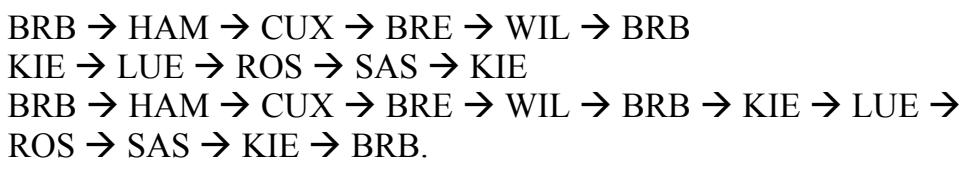

The sub-tour through the North Sea ports has a length of $294 \mathrm{~nm}$ and the tour through the Baltic ports has a length of $389 \mathrm{~nm}$, which sums up to $683 \mathrm{~nm}$. If we now assume a vessel with a speed of 12 knots, then it would need $57 \mathrm{~h}$ for this distance and assuming that one passage of the NOK takes $10 \mathrm{~h}$ we get $77 \mathrm{~h}$, which is 3 days and $5 \mathrm{~h}$. However, we have to be aware that we did not include the time for loading and unloading the vessel. The total demand of LNG per day in all ports is 790.93 tons, as we do not need to supply Brunsbüttel. Hence, in 4 days we need to move 3163.72 tons on and from board. 
Currently, it can be assumed that $1000 \mathrm{~m} 3 \mathrm{LNG}$ can be loaded/unloaded per hour, which corresponds to 468.1 tons of LNG (Olaniyi \& Gerlitz, 2019). This would last 14 hours, so a tour to supply all ports would take 3 days and $19 \mathrm{~h}$ and a time-step equalling 4 days would be sufficient. As we have the possibility to refill the LNG-vessel each time we pass through the port of Brunsbüttel the vessel only needs the maximum demand of the subgraphs it is supplying. The maximum is achieved on the North Sea subgraph with 448.77 tons per day and since the time-horizon is four days, the vessel needs to have a capacity of 1795.08 tons, which corresponds to $3834.82 \mathrm{~m} 3$, so a capacity of about $4000 \mathrm{~m} 3$ would be sufficient. The resulting TSP tour is shown in Figure 2:

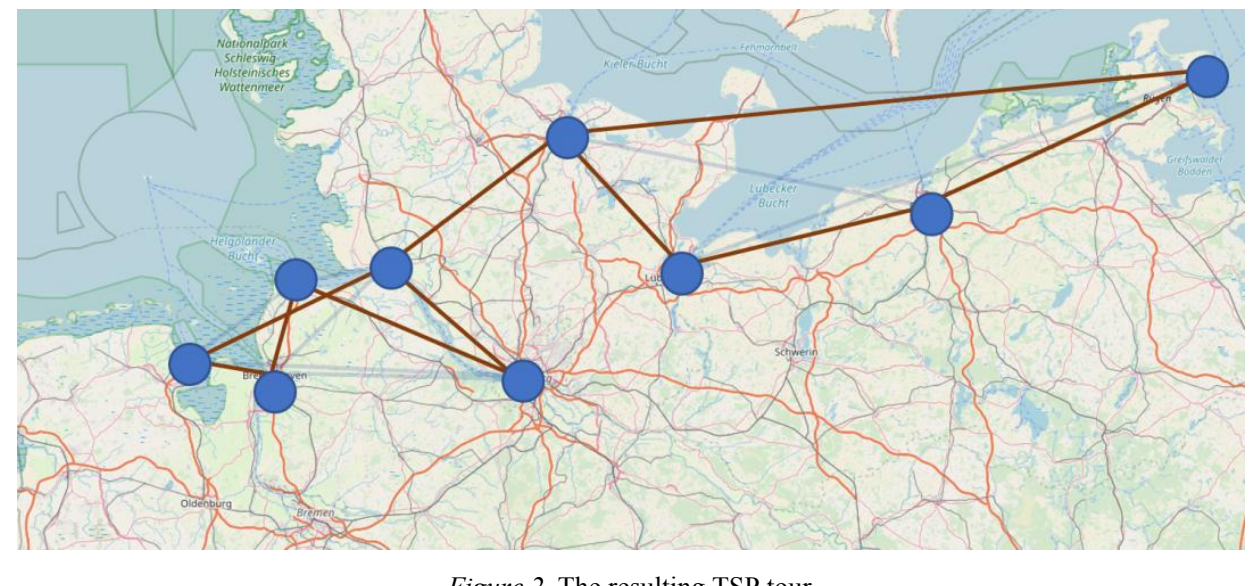

Figure 2. The resulting TSP tour

Figure 2 highlights that that the result of the TSP analysis leads to an optimal tour graph that is connected and which consists of two sub-graphs, the western sub-graph consists of all vertices representing all North Sea ports whereas the eastern sub-graph represents all Baltic ports. The connecting edge of these two sub-graph represents the Kiel Canal (NOK) that has to be passed by a LG supply vessel. A passage of the NOK in one direction requires 10 hours and generates additional costs because of canal dues that have to be taken under account.

We will consider the usage of two different vessel types for the LNG distribution, i.e. first we consider a vessel with a LNG capacity of $5000 \mathrm{~m}^{3}=2340.5 \mathrm{t}$, which represents cargo-carrying capacity of $3000 \mathrm{dwt}$. The second vessel type is assumed to have a LNG transport capacity of $7500 \mathrm{~m}^{3}=3510.75 \mathrm{t}$, representing a cargo-carrying capacity of $6000 \mathrm{dwt}$. Both vessel types are able to pass the Kiel Canal (NOK) as well as there are no problems for these ship types to call all German ports.

Next step is the determination of the costs for distributing the LNG with the vessel among the different ports. Maritime economics split the main costs for running a ship into operation costs and voyage costs (Stopford, 2009). Literature review reveals that there are different studies concerning operation costs for vessels. One well-known international study (PBSL, 2017) fixes as daily operation costs to 7620 US\$ for Handysize vessels (25000 dwt) and to 8400 US\$ for Supramax vessels (55000 $\mathrm{dwt}$ ). Since the analysis of the daily vessel costs are expressed in US\$ and our research takes place in Europe, we are using for our calculations Euro as a currency by applying an exchange course of $1 \mathrm{US} \$=0.90 €$. Now it is possible to derive the daily operation costs of our two vessels by assuming a logarithmic correlation between the daily operating costs in US\$ and the deadweight tonnage (dwt) of a vessel, which yields the regression function $\mathrm{f}(\mathrm{x})=-2398+989.27 * \ln (\mathrm{x})$. As a result, we gain for the 5000 $\mathrm{m}^{3}$-vessel daily operation costs of $5522 \$$, i.e. $4970 €$, and for $7500 \mathrm{~m}^{3}$-vessel 6208 \$, i.e. $5587 €$.

After having fixed the daily operation costs of the vessels, it is necessary to determine the edgeweights for the underlying graph representing the costs for travelling along the edges. These costs are called voyage costs in shipping sector and they include fuel costs and canal dues (Stopford, 2009). For the estimations of the voyage costs for each edge in the graph, we assume that both vessels will use ULSFO due to the SECA regulations for Northern and Baltic Sea that only allow the usage of low Sulphur fuel up to $0.1 \%$ Sulphur content.

As reference price per metric ton ULSFO, we take the average of ULSFO - price for the time 2016-2019 at the Port of Rotterdam, which ranged in the average around $450 €$ per ton (ECG, 2020). Furthermore, we assume a fuel consumption of 10 tons per day for the $5000 \mathrm{~m}^{3}$-vessel and a fuel consumption of 12 tons per day for the $7500 \mathrm{~m}^{3}$-vessel, yielding a consumption of 0.42 and 0.5 tons per hour (MAN, 2019). From this we derivate that one hour of traveling by each ship costs $189 €$ and $225 €$ respectively just for the fuel. 
Since the voyage costs also comprise the canal dues, we have to take under account also the fee for the passage through the NOK, which represents for both vessels $5729 €(\mathrm{NOK}, 2019)$. Hence, we set the voyage costs for travelling each edge to its length multiplied with the fuel costs of one hour, divided by the assumed average speed of the vessels. Additionally, we add the Kiel Canal (NOK) due to the edge (BRB, KIE) representing a passage through the Kiel Canal. Thus, we obtain the following costs for each edge for a $5000 \mathrm{~m}^{3}$ and a $7500 \mathrm{~m}^{3}$ vessel in $€$, where the upper figure represents the voyage costs along an edge of the graph for the smaller vessel and the lower amount in each cell of Table 4 shows the voyage costs for the larger vessel:

Table 4. Voyage costs between the German ports (author's calculation)

\begin{tabular}{|c|c|c|c|c|c|c|c|c|c|}
\hline $\begin{array}{l}5000 \mathrm{~m}^{3} \\
7500 \mathrm{~m}^{3} \\
\text {-vessel }\end{array}$ & BRB & BRE & CUX & HAM & WIL & KIE & LUE & ROS & SAS \\
\hline BRB & & $\begin{array}{l}1276 \\
1519\end{array}$ & $\begin{array}{l}252 \\
300\end{array}$ & $\begin{array}{l}567 \\
675\end{array}$ & $\begin{array}{l}1229 \\
1463\end{array}$ & $\begin{array}{l}7619 \\
7979\end{array}$ & & & \\
\hline BRE & & & $\begin{array}{l}1024 \\
1219\end{array}$ & $\begin{array}{l}1843 \\
2194\end{array}$ & $\begin{array}{c}992 \\
1181\end{array}$ & & & & \\
\hline CUX & & & & $\begin{array}{l}819 \\
975\end{array}$ & $\begin{array}{c}977 \\
1163\end{array}$ & & & & \\
\hline HAM & & & & & $\begin{array}{l}1796 \\
2138\end{array}$ & & & & \\
\hline KIE & & & & & & & $\begin{array}{l}1528 \\
1819\end{array}$ & $\begin{array}{l}1323 \\
1575\end{array}$ & $\begin{array}{l}2268 \\
2700\end{array}$ \\
\hline LUE & & & & & & & & $\begin{array}{c}945 \\
1125\end{array}$ & $\begin{array}{l}2063 \\
2456\end{array}$ \\
\hline ROS & & & & & & & & & $\begin{array}{l}1386 \\
1650\end{array}$ \\
\hline
\end{tabular}

The LNG supply of the German ports with one vessel requires a couple of days so in order to be able to safeguard the LNG distribution with one vessel it is necessary to install LNG storage facilities in the ports to buffer the daily LNG demand for several days. Since both vessels enjoy the same service speed, pre-calculations in the graph reveal that it is possible to limit the time span for the LNG storage to four days. Hence, based on the daily demand of the ports, we calculate to each port the demand of four days so that the availability of LNG fuel through the storages in each port is guaranteed for minimum four days. The corresponding figures of the four-day LNG demand in metric tons of the ports can be found in the following Table 5:

Table 5. Four-day LNG demand of German ports (author's calculation)

\begin{tabular}{|c|c|c|c|c|c|c|c|c|}
\hline & BRE & CUX & HAM & WIL & KIE & LUE & ROS & SAS \\
\hline $\begin{array}{c}\text { Demand in } \\
\text { each time- } \\
\text { step }\end{array}$ & 700.28 & 88.76 & 815.36 & 190.68 & 708.72 & 301.2 & 302.72 & 56 \\
\hline
\end{tabular}

These four-day demands will be integrated in our model together with the costs of the storing facilities of LNG at each port. From the business perspective, it has to be mentioned that installation of LNG storage facilities is related with additional costs, but related logistics services also come along with the possibility of emerging entrepreneurial activities (Prause, 2014b). For the estimations of the storage costs of LNG in the ports, we refer to an international study of Enagas (2016) that fixes the storage costs of LNG with a calorific value of $1 \mathrm{GWh}$ to an amount of $32.40 €$ per day. By transferring these LNG storage costs on a base of metric tons, we obtain a price of $453.60 €$ per day and per ton LNG. The transformation from GWh into tons is realized by taking under account the calorific value of $14 \frac{\mathrm{kWh}}{\mathrm{kg}}$ for LNG.

Equipped with this data, we are finally able to set up a more sophisticated Mixed Integer Program formulation of the IRP. For the calculation, we will again take the graph $G=(V, E)$, where $V$ is the set of the ports and $\mathrm{E}$ is the set of edges that we described in methodology part of the paper. However this time, we consider the complete graph between ports in the North and Baltic Sea and the two edges (BRB, KIE) and (BRB, KI2) connecting the two subgraphs. 
For the mathematical formulation of the new model, we have to introduce larger number of sets parameter and variable that are presented in the following list:

Sets

- $\quad N S:=\{B R E, C U X, H A M, W I L\}$ the set of the ports at the North Sea

- $B A L:=\{K I E, K I 2, L U E, R O S, S A S\}$ the set of the ports at the Baltic Sea

- $M:=N S \cup B A L$

- $M^{\prime}:=M \cup\{B R B\}$

- $E$ the set of edges between the ports

- $T:=\{1, \ldots, H\}$ the set of discrete time-steps

- $T_{0}:=\{0, \ldots, H\}$

- $T^{\prime}:=\{1, \ldots, H+1\}$

- $T_{0}{ }^{\prime}:=\{0, \ldots, H+1\}$

Parameters

- $\quad H$ is the time-horizon, i.e., the last time-step of the model

- $\quad c_{i j}$ is the shipping cost of the edge $i j \in E$ given by the cost-matrix

- $r_{i}$ is the LNG-demand of port $i \in M$ for 4 days given above

- $\quad$ cap is the capacity of the vessel

- $c_{\text {stor daily }}$ are the daily storage costs for one ton of LNG

- $c_{\text {opex }}$ daily are the daily operation costs of the used vessel

Variables

- $\quad x_{i t} \geq 0 \forall i \in M, t \in T_{0}$ a continuous variable determining how much LNG is distributed to port $\mathrm{i}$ at time $\mathrm{t}$

- $y_{i j t} \in\{0,1\} \forall i j \in E, t \in T$ a binary decision variable determining if edge ij is used at time t, where additionally $y_{B R B, j, t}, y_{i, B R B, t} \in\{0,1,2\} \forall i, j \in M, t \in T$

- $z_{i t} \in\{0,1\} \forall i \in M^{\prime}, t \in T$ a binary decision variable determining if port i receives a delivery at time $\mathrm{t}$ or not

- $\quad I_{i t} \geq 0 \forall i \in M, t \in T_{0}{ }^{\prime}$ the inventory at port $\mathrm{i}$ at time $\mathrm{t}$

- $\quad I_{i}^{\text {cap }} \geq 0 \forall i \in M$ a continuous variable determining the max. capacity of LNG-storage at port $\mathrm{i}$

- $c_{\text {opex }} \geq 0$ is the operation costs of the time-period of the current vessel

- $\quad c_{\text {stor }} \geq 0$ are the storage costs of the considered time-period

- $c_{\text {voy }} \geq 0$ are the voyage costs of the considered time-period

With these definitions, we are able to formulate our mixed integer program (MIP) for the calculation of the underlying IPR for model A. Again, the main objective of our calculations is the minimization of the overall costs of the LNG-distribution to the German ports. The overall or total costs are driven by the operation costs and the transport costs for the LNG-deliveries. In addition to that, also the storage costs have to be taken under account since in case of inter-arrival times of LNG-supply of more than one days the LNG demands in the port have to be bridged by taking fuel from the LNG-storage in the port. Hence, the equations of the IPR model have to safeguard that the LNG-storage in the ports will never be empty which cause additional equations.

The LNG-storing at the ports represents a decent issue in the whole analysis. We saw already that we have to estimate $453.60 €$ per day and per ton LNG for storing. These storage costs are so high that from the economic point of view a daily LNG-supply to the ports are more cost efficient than the utilization of storages. Hence, by reducing the research question only to the financial dimension the LNGsupply via vessels like advocated in model A would be no option because the LNG-supply with ships is not possible on daily basis with reasonable cost levels. Therefore, we include in our assessment also other dimensions like environmental aspects. Nevertheless, the LNG-storage costs have to be mentioned and the research has not to answer who will be responsible for the coverage of the LNG-storing at the ports, i.e. if the costs for LNG-storage are paid e.g. by public sources then they out of our cost considerations.

Coming back to the formulation of our mixed integer program (MIP) for the description of the underlying IPR, we are now able to present in the following table 6 the IPR equations for model A for the LNG-distribution by ships. As already mentioned, we use the above-defined sets, parameters and variable in the equations for model $\mathrm{A}$ in Table 6 : 
Table 6. IPR equations for model A

$$
\begin{aligned}
& \text { (IRP) } \\
& \min c_{\text {voy }}+c_{\text {stor }}+c_{\text {opex }} \\
& \begin{array}{lll}
\text { s.t. } & I_{i 0}=r_{i} \quad \forall i \in M
\end{array} \\
& x_{i 0}=0 \quad \forall i \in M \\
& I_{i t}=I_{i, t-1}+x_{i, t-1}-r_{i} \quad \forall i \in M, t \in T^{\prime} \\
& I_{i t} \geq 0 \quad \forall i \in M, t \in T^{\prime} \\
& x_{i t} \geq I_{i}^{c a p} * z_{i t}-I_{i t} \quad \forall i \in M, t \in T \\
& x_{i t} \leq I_{i}^{c a p}-I_{i t} \quad \forall i \in M, t \in T \\
& x_{i t} \leq I_{i}^{\text {cap }} * z_{i t} \quad \forall i \in M, t \in T \\
& \sum_{i \in N S} x_{i t} \leq \operatorname{cap} \quad \forall t \in T \\
& \sum_{i \in B A L} x_{i t} \leq \operatorname{cap} \quad \forall t \in T \\
& \sum_{i \in N S} x_{i t} \leq \operatorname{cap} * z_{B R B, t} \quad \forall t \in T \\
& \sum_{i \in B A L} x_{i t} \leq \operatorname{cap} * Z_{B R B, t} \quad \forall t \in T \\
& \sum_{j: i j \in E} y_{i j t}+y_{j i t}=2 * z_{i t} \quad \forall i \in M, t \in T \\
& \sum_{i \in S: i j \in E} \sum_{j \in S} y_{i j t} \leq|S|-1 \quad \forall S \subseteq M: 2 \leq|S| \leq|M|-1, \forall t \in T \\
& y_{i j t}+y_{j i t} \leq 1 \\
& c_{v o y}=\sum_{i j \in E} \sum_{t \in T} c_{i j} y_{i j t} \\
& c_{\text {stor }}=4 * c_{\text {stor }} \text { daily } * H * \sum_{i \in M} I_{i}^{\text {cap }} \\
& c_{\text {opex }}=4 * c_{\text {opex daily }_{\text {dil }}} * H \\
& x_{i t} \geq 0 \\
& y_{i j t} \in\{0,1\} \\
& y_{i j t} \in\{0,1,2\} \\
& z_{i t} \in\{0,1\} \\
& I_{i t} \geq 0 \\
& I_{i}^{\text {cap }} \geq 0 \\
& c_{\text {opex }} \geq 0 \\
& c_{\text {stor }} \geq 0 \\
& c_{\text {voy }} \geq 0
\end{aligned}
$$

The objective function of our model (A.1) aims at minimizing the total costs, consisting of the transportation costs (A.16), the storage costs (A.17) and the operation costs (A.18).

The constraints (A.2) and (A.3) ensure that all storages can satisfy the demand at time $t=0$. In addition to that, the first delivery takes place at time $t=1$, while (A.4) determines the inventory at time $t$ to be the old inventory plus the supply that arrived in the previous time-step minus the amount of LNG that is used during this moment of time. And that the amount of stored LNG is never negative is satisfied by constraint (A.5). Further, constraints (A.6)-(A.8) ensure that only deliveries up to the possible storage-capacities are possible and (A.9)-(A.12) are capacity-constraints guaranteeing that we only load as much LNG as the vessel can load. In contrast to (Archetti et al., 2007), we split the constraint into two because we have to subgraphs that are only connected by a single bridge, i.e., the Kiel Canal (NOK), so whenever the vessel is switching between the two subgraphs we are able to reload it because the vessel has to go through BRB.

Constraint (A.13) determines that the vessel has to leave each city it supplies as two of the incident edges have to be active if it is supplied. This constraint has to hold for all cities apart from Brunsbüttel 
(BRB), as the vessel might visit BRB more than one time to reload and switch between the Baltic and North Sea subgraphs. (A.14) is the sub-tour-elimination constraint of (Dantzig et al., 1954) that is used to get rid of sub-tours in the resulting route. Further, we only allow one of the parallel edges to be active, which is safeguarded by constraint (A.15).

Based on this model it is again possible to obtain a solution by using again SCIP (Gleixner et al., 2018). Since we are interested in the analysis on annual base and we consider a maximal period of a fourday delivery at each port, our time-horizon $\mathrm{H}$ has to be 91 , i.e. $\mathrm{H}=91$, to cover one year. By taking under consideration all these frame conditions we the results that are consolidated in table 7 :

Table 7. LNG-distribution costs for model A (author's calculation)

\begin{tabular}{|l|c|c|}
\hline Vessel size & $5000 \mathrm{~m}^{3}$ & $7500 \mathrm{~m}^{3}$ \\
\hline Voyage costs & $2365636 €$ & $2617615 €$ \\
\hline Operation costs & $1809080 €$ & $2033668 €$ \\
\hline Total distribution costs & $4174716 €$ & $4651283 €$ \\
\hline
\end{tabular}

An short analysis of the costs of the results of model A reveals a cost advantage of about 500000 $€$ for the LNG-distribution with the $5000 \mathrm{~m}^{3}$ vessel compared the use of the larger $7500 \mathrm{~m}^{3}$ vessel. However, the results of table 7 are not taking under account the storage costs that appear at the different ports and that sum up to $522363075 €$. This result points out that in both cases the LNG-storage costs in the ports are responsible for more than $99 \%$ of the accruing costs. Hence, the question raises who will pay for the storage costs and how it reduce these posts.

Related to the optimal cost solution of model A, there corresponds also an optimal tour that has to be travelled by the vessel within each 4 days to safeguard the LNG supply in the ports. The LNG-storages at the ports are dimensioned so that they are able to buffer the needed LNG-demand at each port. The optimal tour consists of three different routes, namely the North Sea ports, the Hamburg tour and the Baltic ports tour, i.e. the German Baltic ports are served in one tour, there exists one tour only suppling Hamburg and the third tour calls all North Sea ports except Hamburg. All tours comprise the time for unloading LNG in the ports and in addition to that, especially for the Baltic tour, the time for passing the Kiel Canal (NOK) of twice 10h. A more detailed view allow the following overview:

- North Sea ports tour

$\circ \mathrm{BRB} \rightarrow \mathrm{CUX} \rightarrow \mathrm{BRE} \rightarrow \mathrm{WIL} \rightarrow \mathrm{BRB}$

L Length of tour: ca. $22 \mathrm{~h}$

- Hamburg tour

$\circ \mathrm{BRB} \rightarrow \mathrm{HAM} \rightarrow \mathrm{BRB}$

- Length of tour: ca. $8 \mathrm{~h}$

- Baltic ports tour

$$
\circ \mathrm{BRB} \rightarrow \mathrm{KIE} \rightarrow \mathrm{LUE} \rightarrow \mathrm{ROS} \rightarrow \mathrm{SAS} \rightarrow \mathrm{KIE} \rightarrow \mathrm{BRB}
$$

○ Length of tour: ca. $56 \mathrm{~h}$

The length of all three tours serving all German ports sum up to a total length of about $86 \mathrm{~h}$, i.e. a roundtrip with calling all German ports requires 4 days, so that enough time is available for charging the vessel with LNG in Brunsbüttel port.

A consideration of model A concerning the storages at the ports reveals that the maximal capacity of the LNG-storages equals the demand of 4 days which implies that the model tries to minimize the storage costs first, i.e., it is cheaper to deliver the demand of the next 4 days but not more. Therefore, we conclude that the transportation costs must be cheaper than the storage costs, even for ports with little demand and huge distances to other ports, as it appears in the case of the Port of Sassnitz (SAS). Thus, one approach to improve the existing optimal routing solution would be to prolong the periods of LNGdeliveries to these ports to more than 4 days. The answer to this question is related to the storage costs of LNG in the ports.

To answer this question, we execute a sensitivity analysis to calculate the maximal price to pay for the storage per ton of LNG so that it makes economically sense to store the LNG demand for more than one time-step in order to reduce the annual number of LNG-deliveries per port. A binary search in the interval $[0,453.6]$ of the storage costs yields maximal prices $5.20 €$ per ton of LNG for a $5000 \mathrm{~m}^{3}$-vessel and $6.19 €$ for a $7500 \mathrm{~m} 3$-vessel. In these cases, it makes sense to cut out SAS of the usual tour and 
deliver only every second time-step. Next changes in the tours occur if the storage costs fall onto a price of $1.30 €\left(5000 \mathrm{~m}^{3}\right)$ and $1.94 €\left(7500 \mathrm{~m}^{3}\right)$ when the Port of Sassnitz (SAS) is only supplied every fourth time-step and all other Baltic ports only every second time-step. However, it has to be pointed out that all these cases can only occur if the storage price decreases by more than $98 \%$ compared with the current value.

\subsection{Model B: LNG-distribution by trucks}

After looking at possible supply strategies by vessels, we now want to compare the results to a distribution by trucks. Therefore, we will tackle the problem on a daily basis, as all ports can be reached by truck within one day, including the return to BRB.

For this model, we assume that each truck has a capacity of 30 tons for LNG transportation, as we use a truck with semitrailer and trailer (15 tons capacity each). In order to fix the corresponding costs of a full LNG supply vehicle, we assume the same costs for the trailer and the semitrailer. The depreciation periods of the trailer and the semitrailer are assumed to be 15 years, whereas the depreciation of the towing vehicle is supposed to be only 10 years. The number of drivers depends on the daily operation time as well as on the annual work time of one driver. Since we assume a 24/7 service of the LNGdistribution trucks and the normal annual working time of an employee in German is $1690 \mathrm{~h}$ we assume that we need 5 drivers to safeguard the service. By taking under account the study results of Bünger et al. (2016) together with outcome of the employment study of the Comite National Routier (2016) we are able to estimate first the related fix costs as well as the costs for the drivers:

- Investment for a trailer/semitrailer:

$207000 €$

$$
\text { - Amortization period: } 15 \text { years }
$$

- Investment for towing vehicle:

$$
\text { - Amortization period: } 10 \text { years }
$$

- Annual employment costs for the drivers:

$101000 €$

- Annual costs for one driver: $46000 €$

$230000 €$

- 5 drivers needed to cover $24 / 7$ service

- Annual tax, insurance, management:
- Trailer/semitrailer:
$10794 €$
○ Towing vehicle:
$15871 €$

These considerations lead to daily fix costs for a truck with a towing vehicle, a trailer and a semitrailer of around $840 €$. In accordance with the notation of model A we will call daily fix costs also operation costs.

For the calculation of the variable costs per kilometer, we refer again to the already mentioned studies on truck transportation to fix the servicing costs as well as depreciation for the towing vehicle. The last missing variable cost components concern road toll for trucks in Germany and fuel costs. The German road toll can be gained from the public pricing system and the fuel costs are estimated on the assumption that the vehicle consumes 31 litres of diesel per $100 \mathrm{~km}$ with a price of $1.20 €$ per litre. Altogether, the variable cost rate per kilometer sums up to $0.82 €$ per driven kilometre based on the following costs:

- Fuel costs per km:

$0.3720 €$

- Servicing:
- Trailer/semitrailer:
$0.0471 €$
○ Towing vehicle:
$0.1705 €$
$0.1870 €$

- Road toll:

The variable costs per kilometer for the use of the LNG distribution vehicle we will call in the sequel also transportation costs. Provided with this data, we conclude that a truck with trailer and semitrailer has daily operation costs of $840 €$ and transportation costs of $0.82 €$ per km.

After having fixed the costs related to the road-based LNG supply, we have to calculate the number of daily full-truck-loads (FTL) that are necessary to feed the LNG demand in the ports. Therefore, we assume that the demand delivered by one truck, is supplied by this truck directly and this truck is returning to the Port of Brunsbüttel (BRB), i.e. by taking under account the given daily demand. Moreover, by assuming an average truck speed of $60 \frac{\mathrm{km}}{\mathrm{h}}$, we obtain the following number of tours a truck can perform per day to each destination, i.e. we are able to show the result of the calculation in the following Table 8: 
Table 8. LNG demand calculation with trucks (author's calculation)

\begin{tabular}{|c|c|c|c|c|c|c|c|c|c|}
\hline & BRE & CUX & HAM & WIL & KIE & LUE & ROS & SAS & $\Sigma$ \\
\hline $\begin{array}{c}\text { Demand per day } \\
\text { in tons }\end{array}$ & 175.07 & 22.19 & 203.84 & 47.67 & 177.18 & 75.3 & 75.68 & 14.0 & 790.93 \\
\hline $\begin{array}{c}\text { Daily needed } \\
\text { FTL }\end{array}$ & 5 & 0 & 6 & 1 & 5 & 2 & 2 & 0 & 21 \\
\hline $\begin{array}{c}\text { Daily transport } \\
\text { costs in } €\end{array}$ & 1722 & - & 935 & 443 & 820 & 443 & 787 & - & 5150 \\
\hline $\begin{array}{c}\text { Max \# of daily } \\
\text { tours to port }\end{array}$ & 3 & 3 & 7 & 2 & 6 & 5 & 3 & 1 & \\
\hline FTL needed & 0.836 & 0.74 & 0.795 & 0.589 & 0.906 & 0.51 & 0.523 & 0.467 & 5.366 \\
\hline
\end{tabular}

Hence, two trucks are needed to supply BRE, and one additional truck for the supply of each destination comprising the Ports of Hamburg (HAM), Wilhelmshaven (WIL), Kiel (KIE), Lübeck (LUE) and Rostock (ROS), which sums to a total number of seven needed trucks. An analysis of the related costs reveals daily total costs of $11030 €$ that are composed by $5880 €$ daily fix costs for the truck use plus $5150 €$ for daily variable costs due to the LNG transport to the ports. In addition to this information, table 6 also discloses the number of full-truck-loads each port needs to satisfy the demand. Consequently table 6 points out that we need at least six and at most eight additional truck deliveries to satisfy the daily demands.

However, for the determination of the number of needed trucks and the way, how to supply the demand as cheap as possible a linear optimization program has to be solved. Therefore, we will set up a mixed integer program (MIP) formulation of the vehicle routing problem (VRP), which we derive from the IRP formulation of (Archetti et al., 2007) using again the sub-tour elimination constraints of (Dantzig et al., 1954). The related distances we take from street-distance-matrix of table 3 and the costs for the edges of the underlying graph is depicted in the following Table 9:

Table 9. Travel costs for trucks (author's calculation)

\begin{tabular}{|c|c|c|c|c|c|c|c|c|c|}
\hline in $€$ & BRB & BRE & CUX & HAM & WIL & KIE & LUE & ROS & SAS \\
\hline BRB & & 172 & 168 & 78 & 221 & 82 & 111 & 197 & 308 \\
\hline BRE & & & 37 & 111 & 66 & 217 & 205 & 299 & 402 \\
\hline CUX & & & & 94 & 90 & 131 & 234 & 332 & 431 \\
\hline HAM & & & & & 168 & 86 & 74 & 164 & 267 \\
\hline WIL & & & & & & 258 & 246 & 340 & 442 \\
\hline KIE & & & & & & & 66 & 176 & 279 \\
\hline LUE & & & & & & & & 115 & 213 \\
\hline ROS & & & & & & & & & 98 \\
\hline
\end{tabular}

Like in model A we have to define for the truck based model as well sets, parameters and variables in order to formulate the equations for the :

Sets

- $\quad R:=\{1, \ldots, p\}$ the set of possible vehicles,

- $\quad M:=\{B R E, C U X, H A M, W I L, K I E, L U E, R O S, S A S\}$ the set of ports,

- $M^{\prime}:=M \cup\{B R B\}$,

- $E$ the set of edges, given by the street-distance-matrix from above.

Parameters

- $\quad p$ is the maximal number of available trucks,

- $\quad c_{i j}$ the costs of traveling edge $i j \in E$ given by the costs from the begin of this model,

- $d_{i}$ the demand of port $i \in M$,

- $c_{\text {opex }}$ aily are the daily operation costs of one truck.

Variables

- $\quad x_{r i} \geq 0$ the amount of LNG truck $\mathrm{r}$ delivers to port $i$,

- $\quad y_{r i j} \in\{0,1\}$ a binary decision variable determining if vehicle $\mathrm{r}$ is using edge ij or not. If $i=B R B$, then $y_{r i j} \in\{0,1,2\}$, as we allow a truck to take the same route back to the depot it already used,

- $s_{r i} \in\{0,1\}$ determines if vehicle $\mathrm{r}$ takes part in the supply of port $\mathrm{i}$ or not,

- $z_{r} \in\{0,1\}$ determines if truck $\mathrm{r}$ is used or not,

- $c_{\text {opex }} \geq 0$ is the operation costs of the used trucks,

- $c_{\text {trans }} \geq 0$ are the transportation costs. 
Equipped with these definitions we are now able to state the mathematical equations of model B by again trying to minimize the total costs of the supply by trucks. The MIP program for the corresponding vehicle routing problem (VRP) can be found in the following Table 10:

Table 10. VRP for model B

$$
\begin{aligned}
& \text { (VRP) } \\
& \min \\
& c_{\text {trans }}+c_{\text {opex }} \\
& \text { s.t. } \sum_{j \in M^{\prime}: i j \in E} y_{r i j}+y_{r j i}=s_{r i} \quad \forall i \in M, r \in R \\
& \sum_{j \in M} y_{r, B R B, j}=z_{r} \quad \forall r \in R \\
& \begin{array}{lll}
\sum_{r \in R} x_{r i}=d_{i} & \forall i \in M \\
\sum_{i \in M} x_{r i} \leq 1 & \forall r \in R
\end{array} \\
& \sum_{i \in S: i j \in E} \sum_{j \in S} y_{r i j} \leq|S|-1 \quad \forall S \subseteq M: 2 \leq|S| \leq|M|-1, \forall r \in R \\
& x_{r i} \leq s_{r i} \quad \forall r \in R, i \in M \\
& \sum_{i \in M} s_{r i} \leq|M| * z_{r} \quad \forall r \in R \\
& c_{\text {trans }}=\sum_{r \in R} \sum_{i j \in E} c_{i j} * y_{r i j} \\
& c_{\text {opex }}=c_{\text {opex }_{\text {daily }}} * \sum_{r \in R} z_{r} \\
& x_{r i} \geq 0 \\
& y_{r i j} \in\{0,1\} \\
& y_{r i j} \in\{0,1,2\} \\
& s_{r i} \in\{0,1\} \\
& z_{r} \in\{0,1\} \\
& c_{\text {opex }} \geq 0 \\
& c_{\text {trans }} \geq 0
\end{aligned}
$$

The objective function (B.1) of this model aims at minimizing the total costs, consisting of transportation (B.9) and operation costs (B.10). Constraints (B.2) and (B.3) ensure, that whenever a vehicle delivers LNG to a customer it has to arrive and leave this port and that all used vehicles start and end their tours at Port of Brunsbüttel (BRB). Further, constraints (B.4) and (B.5) guarantee that the demand at each port is satisfied and each truck cannot load more than one full truckload. Here we consider the leftover demand after the direct deliveries as the demand of each port and each demand is in the interval $[0,1]$ as there cannot be a demand greater than one truckload after the supply of the full truckloads.

(B.6) is again a constraint ensuring that the tour of each vehicle does not contain a subtour according to (Dantzig et al., 1954). Finally, constraints (B.7) and (B.8) define the number of vehicles that are used, and which port is delivered by which truck.

In the same way like in the case of model A, we apply again the SCIP software to find an optimal solution. The solution of model B leads to a solution consisting of six routes for the LNG delivery with trucks to the ports, i.e. all of these routes are land-based and have to be travelled by the LNG-supply truck fleet. There are two routes serving only one port, namely Baltic ports in Kiel and Lübeck, and the other four combined routes are serving two ports in one round trip. The ports in Hamburg and Bremen are part of two routes due to high LNG volumes that are needed in these ports:

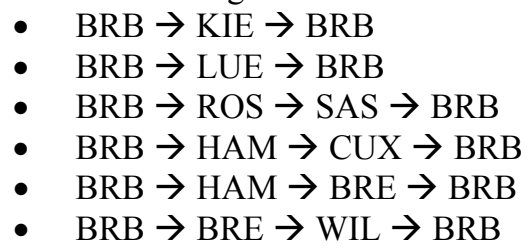

- $\quad \mathrm{BRB} \rightarrow \mathrm{KIE} \rightarrow \mathrm{BRB}$

- $\quad \mathrm{BRB} \rightarrow \mathrm{LUE} \rightarrow \mathrm{BRB}$

- $\mathrm{BRB} \rightarrow \mathrm{ROS} \rightarrow \mathrm{SAS} \rightarrow \mathrm{BRB}$

- $\mathrm{BRB} \rightarrow \mathrm{HAM} \rightarrow \mathrm{CUX} \rightarrow \mathrm{BRB}$

- $\mathrm{BRB} \rightarrow \mathrm{HAM} \rightarrow \mathrm{BRE} \rightarrow \mathrm{BRB}$

- $\mathrm{BRB} \rightarrow \mathrm{BRE} \rightarrow \mathrm{WIL} \rightarrow \mathrm{BRB}$ 
The resulting routing-plan uses six trucks and causes daily operation costs of $5040 €$ and $2148 €$ of transportation costs for the not fully loaded LTL - deliveries, which have to be added to the already known costs that are caused by the full-truck-loads (FTL), which were already identified to amount 11030 $€$ as daily total costs. Thus, the calculation for the resulting daily total costs yields $18218 €$ comprising daily operation costs of $10920 €$ as well as daily transportation costs of $7298 €$. As these figures stem from a model on daily base, we obtain yearly total distribution costs of $6649570 €$ for with trucks as we can see in the following Table 11:

Table 11. LNG supply costs of model B (author's calculation)

\begin{tabular}{|l|c|}
\hline \multicolumn{1}{|c|}{ Cost category } & Annual supply costs \\
\hline Transportation costs for direct deliveries & $1879750 €$ \\
\hline Transportation costs for combined routes & $784020 €$ \\
\hline Total transportation costs & $2663770 €$ \\
\hline Operation costs for direct deliveries & $2146200 €$ \\
\hline Operation costs for combined routes & $1839600 €$ \\
\hline Total Operation costs & $3985800 €$ \\
\hline Total costs in $€$ & $\mathbf{6 6 4 9 5 7 0 €}$ \\
\hline
\end{tabular}

A comparison of the pure total distribution costs of the $5000 \mathrm{~m} 3$-vessel and the road-based LNGdistribution by trucks reveals the vessel is more economic than the truck with annual distribution costs of about $4175 \mathrm{t} €$ compared to $6650 \mathrm{t} €$, i.e. expressing a cost advantage of about $2500 \mathrm{t} €$ for the vessel. However, the pure distribution costs neglect the needed LNG-storage needs in the ports, which has to be taken also under account.

The inclusion of the LNG storage costs leads to another result that is presented for the truck situation in the following Table 12:

Table 12. Comparison of the LNG supply costs

\begin{tabular}{|l|c|c|c|}
\hline Cost categories in $€$ & Trucks & $\mathbf{5 0 0 0} \mathbf{~ m}^{\mathbf{3}}$-vessel & $\mathbf{7 5 0 0} \mathbf{~ m}^{\mathbf{3}}$-vessel \\
\hline Operation costs & $3985800 €$ & $1809080 €$ & $2033668 €$ \\
\hline Transportation costs & $2663770 €$ & $2365636 €$ & $2617615 €$ \\
\hline Total distribution costs & $\mathbf{6 6 4 9 5 7 0 €}$ & $\mathbf{4 1 7 4 7 1 6 €}$ & $\mathbf{4 6 5 1 2 8 3 €}$ \\
\hline
\end{tabular}

A comparison of model A and B including the storage costs in the ports reveals that LNG-supply by trucks is less than half as expensive than the distribution with the $5000 \mathrm{~m} 3$-vessel. The reason is easy to explain because the truck distribution is faster than the vessel use, which reduces the capacity of the storage facilities in the ports to one day plus safety stock compared to four days plus safety stock in the case of the sea-bound distribution of model A.

Since the storage costs are the main reason for the disadvantage of model A, we again perform a sensitivity analysis to investigate at which storage price the vessels outperform the truck distribution from an economical point of view. Like in the case of model A, a binary search in the interval $[0,453.6]$ is executed with the result that the costs of storage have to be $2.89 €$ and respectively $2.38 €$ to achieve that the $5000 \mathrm{~m} 3$-vessel and the $7500 \mathrm{~m} 3$-vessel would be cheaper than the truck concerning the total costs of the two LNG-distribution models. Consequently, we are able to conclude that the LNG-distribution by vessels becomes only economically more favorable than the truck supply of model B if the costs for storing LNG may decrease dramatically. The situation with storage costs shows Table 13:

Table 13. Comparison of the LNG supply costs including storage

\begin{tabular}{|l|r|r|r|}
\hline \multicolumn{1}{|c|}{ Cost categories in $\boldsymbol{€}$} & Trucks & $\mathbf{5 0 0 0} \mathbf{~ m}^{\mathbf{3}}$-vessel & $\mathbf{7 5 0 0} \mathbf{~ m}^{\mathbf{3}}$-vessel \\
\hline Operation costs & 3985800.00 & 1809080.00 & 2033668.00 \\
\hline Transportation costs & 2663770.00 & 2365636.00 & 2617615.00 \\
\hline Total distribution costs & 6649570.00 & 4174716.00 & 4651283.00 \\
\hline Storage costs & 130949534.52 & 522363074.69 & 522363074.69 \\
\hline Cost of safety stock (1 day) & 130949534.52 & 130949534.52 & 130949534.52 \\
\hline Total storage costs & 261899069.04 & 653312609.21 & 653312609.21 \\
\hline Total costs & $\mathbf{2 6 8 5 4 8 6 3 9 . 5 4}$ & $\mathbf{6 5 7 4 8 7 3 2 5 . 2 1}$ & $\mathbf{6 5 7 9 6 3 8 9 2 . 2 1}$ \\
\hline
\end{tabular}

The high LNG storage costs in the ports are often solved by using LNG trucks together with their trailers as mobile LNG storage, i.e. it would result in a truck-to-ship LNG bunkering. With such a solution, it would possible to eliminate the LNG storage costs in model B but it requires a higher number 
of truck equipment to safeguard the LNG supply for the calling ships. An additional calculation shows that such a truck-to-ship bunkering of LNG requires 19 fully equipped trucks and would yield total LNG supply costs of 7.43 million $€$. A calculation furthermore shows that such a truck-to-ship solution would lead to additional distribution costs of $25.60 €$ for every suppled ton of LNG in the ports. An amount of ca. $25 €$ per ton for the LNG supply service seems to be still realistic compared to other solutions including $\mathrm{LNG}$ storage at the ports.

\subsection{Model C: Combined distribution mode}

A In the third model, we combine the two previous distribution models, i.e. we investigate a multimodel LNG-distribution based on vessel and truck. Since in model A the vessels spent the biggest part of the time with supplying the Baltic Sea ports, these ports are responsible for the length of the time-steps in our IRP model. Therefore, it seems to be interesting to consider a model in which a vessel is only used to supply the North Sea ports, while the Baltic ports are supplied by trucks. Consequently, this would lead to a scenario with reduced storage costs because in this case the LNG storage is only necessary on a daily basis. Hence, our idea is to combine the vessel-based LNG-supply in the North Sea with a truck-based distribution for the Baltic ports.

The assumption that the vessel uses the same route as in model A, yields that at most $294 \mathrm{~nm}$ have to be travelled per time-step and that the maximal LNG-load of the vessel would be 244.93 tons, i.e. 524 $\mathrm{m}^{3}$ of LNG. As we would lose $1.5 \mathrm{~h}$ per day for the loading and unloading of the daily demand of the North Sea ports, the used vessel needs to have a speed of at least 13 knots. Let us furthermore assume that we take under account a $600 \mathrm{~m}^{3}$-vessel with $2500 \mathrm{dwt}$, we obtain operation costs of $4807.88 €$ for such a vessel by applying again the logarithmic regression function for the operation cost. Since such a vessel has nearly the same size as the already considered $5000 \mathrm{~m} 3$-vessel, we can also assume that the fuelconsumption of such a vessel should be about 0.42 tons per hour. In addition to that we can also assume, that such a smaller ship mostly likely is fueled by MGO or ULSFO so that we can take the same average price of $450 €$ per ton like in model A. By putting together these observations we are able to calculate voyage costs of $189 €$ per hour, i.e. we obtain the following voyage costs for the edges of our graph that are disclosed in the Table 14:

Table 14. Voyage costs for North Sea ports

\begin{tabular}{|c|c|c|c|c|}
\hline & BRE & CUX & HAM & WIL \\
\hline BRB & 1178 & 233 & 523 & 1134 \\
\hline BRE & & 945 & 1701 & 916 \\
\hline CUX & & & 756 & 901 \\
\hline HAM & & & & 1657 \\
\hline
\end{tabular}

The result for model $\mathrm{C}$ is achieved by running again model $\mathrm{A}$ for the supply vessel, this time limited to the North Sea ports and by using the data provided in the tables 3. In addition to that, we rerun our model B for the trucks just for the Baltic cities. Hence, we end up with a LNG-delivery situation, in which the North Sea ports are supplied by the same vessel-based solution as for model A; this time restricted to the North Sea, and parallel that the Baltic ports are supplied by a fleet of six trucks in total, using the same routes like in model B. Like in model B, there are three trucks that are dedicated to serve the ports of Kiel, Lübeck and Rostock (in each case one truck) and additional three trucks for common LNG-supply routes.

By focusing on the cost side of the solution for model $\mathrm{C}$, the calculations yield daily costs for using the vessel of $9081.88 €$ that are composed by voyage costs of $4274 €$ and operation costs of 4 $807.88 €$. The daily storage costs for the North Sea ports sum up to $203562.07 €$. The cost situation for the truck-based LNG-supply of the German Baltic Sea ports is the same as in model B, i.e. we are able to use the same figures like in previously. Hence, the annual costs for model $\mathrm{C}$ are described in Table 15:

Table 15. Annual total costs of model C

\begin{tabular}{|c|c|c|c|}
\hline Cost categories in $€$ & Vessel & Full truck loads & Combined truck routes \\
\hline Operation costs & 1754876.20 & 919800 & 919800 \\
\hline Total OPEX & \multicolumn{3}{|c|}{3594476.20} \\
\hline Transport costs & 1560010 & 748250 & 360985 \\
\hline Total Distrib. Costs & \multicolumn{3}{|c|}{2669245} \\
\hline Storage costs & 74300156.28 & \multicolumn{2}{|c|}{56649378.24} \\
\hline Total storage costs & \multicolumn{3}{|c|}{130949534.52} \\
\hline Safety stock costs (1 day) & \multicolumn{3}{|c|}{130949534.52} \\
\hline Total costs & \multicolumn{3}{|c|}{268162790.24} \\
\hline
\end{tabular}


By comparing the results of model $\mathrm{B}$ and model $\mathrm{C}$, we are able to conclude that by taking under account only the cost dimension that model $\mathrm{C}$ is dominated by model $\mathrm{B}$ that has slightly lower LNGdistribution costs. The storage costs in both cases of model $\mathrm{B}$ and model $\mathrm{C}$ are the same. The comparison of model $\mathrm{A}$ and model $\mathrm{C}$ shows that model $\mathrm{C}$ dominates model $\mathrm{A}$ from an economical point of view.

\section{Discussion}

The research investigated three different models for the distribution of LNG between the main German ports modeled in the form of an Inventory Routing Problem (IRP). The three LNG-distribution models utilize different transport modes to supply the German ports comprising ships, trucks and a combination of both leading to the three model A, B and C:

- Model A: LNG-distribution by vessels

- Model B: LNG-distribution by trucks

- Model C: Combined distribution ways.

The investigation uses combinatorial optimization methods in order to find the most reasonable LNG-distribution mode under the viewpoint of green logistics. In accordance with the scientific literature, the three pillars of green logistics correspond to economic, ecologic and social issues and two of these dimensions, namely economic and ecological, are considered for the assessment of the three LNGdistribution model (Hunke \& Prause, 2013; Prause 2014a). The social dimension can be neglected since the working conditions in all three models are comparable and no model comes along with specific social disadvantages. Hence, the two main dimensions of sustainable logistics decisions are represented in the assessment through the costs and emissions of each model and they are complemented by the time (Daduna \& Prause, 2017). Thus, the assessment assigns to each of the three models a 3-dimensional vector with the compnents costs, emissions and time.

Since the costs and the time between two deliveries are well known through the already discussed models, the open question concerns the emissions. In this paper, we evaluate the models by the annual $\mathrm{CO} 2$ emissions. Literature review reveals estimations for the $\mathrm{CO} 2$ emissions of the trucks to be $62 \frac{\mathrm{gCO}}{t \mathrm{~km}}$ and of the vessels to be $20 \frac{\mathrm{g} \mathrm{CO}}{\mathrm{t} \mathrm{km}}$ as average values (Cefic, 2011). With respect to this emission factors and the fact that both vessels realize a performance of $517307.5 \mathrm{tkm}$ per time-step, we conclude that both vessels would emit about 941.5 tons of CO2 per year in scenario A. As we further obtain a logistics performance of $125366.6 \mathrm{tkm}$ per day for scenario $\mathrm{B}$, we can determine the annual $\mathrm{CO} 2 \mathrm{emissions}$ of the distribution by trucks to be 2837 tons. Similarly, as the trucks in scenario C performs $51092.7 \mathrm{tkm}$ and the vessel $53223.6 \mathrm{tkm}$, we arrive at annual CO2 emissions of 1544.8 tons for model C. Consequently, one can conclude that model A enjoys the lowest emission, while scenario $\mathrm{C}$ dominates scenario $\mathrm{B}$ from an ecological point of view.

Finally, for the assessment of the time dimension we take the average inter-arrival time between two LNG-deliveries at the ports. All inter-arrival times have been subject already in the discussions of the results of the calculations so that for model $\mathrm{A}$, the average time between two vessel calls at the ports is four days whereas model $\mathrm{B}$ leads to an average value of one day and the value for model $\mathrm{C}$ is also one day. The time values for the models can be interpreted as flexibility and deliver security since the demands in the ports are only estimated so that random changes in the predicted demands can be balanced within the given timeframes.

Altogether, we now able to assign to each of the three models a 3-dimensional evaluation vector. Since costs, emissions and time represent all short resources, a component is as more favorable as smaller the corresponding value is. The final assessment in form of the evaluation vectors for the three models can be found in the following Table 16:

Table 16. Final assessment of all three models

\begin{tabular}{|c|c|c|c|c|}
\hline Model & Distribution costs & Total costs & CO2 - emissions & Time \\
\hline $\mathbf{A}$ & 4.2 million $€$ & 660 million $€$ & 940 tons & 4 days \\
\hline B & 6.6 million $€$ & 270 million $€$ & 2840 tons & 1 day \\
\hline C & 2.7 million $€$ & 270 million $€$ & 1540 tons & 1 day \\
\hline
\end{tabular}

Coming back to the research question, we can conclude that by only considering the LNG distribution costs model $\mathrm{C}$ is the most economical solution. By enlarging the scope and integrating the storage costs in the ports into the assessment, then model B and C are the most favorable LNG supply modes, while the result of model $\mathrm{B}$ is dominated by model $\mathrm{C}$ with respect to the ecological dimension as well as to the underlying distribution costs. Thus, our recommendation is the usage of model $\mathrm{C}$ since the 
evaluation vector of model $\mathrm{C}$ offers the lowest values with respect to the distribution costs, the total costs as well as with respect to the time. Hence, model $\mathrm{C}$ represents the cheapest solution with respect to the distribution but also concerning the overall costs including LNG storage, its ecological impact is only half as huge as the usage of distribution model $\mathrm{B}$, and the time dimensions are the same. Its solution is only dominated with respect to the ecological dimension by the result of model A since its emission value is greater. However, since model A leads to costs that are about 2.5 times bigger than the costs of model C, which emissions are only about 1.6 times bigger, model $\mathrm{C}$ tends to be the model of choice for the considered research question. Thus, we showed how the distribution can be modeled as an IRP, which LNG-distribution mode is the most economical for the German ports and which modal mix for the LNG supply leads to the greenest distribution. The results of this paper are in-line with the empiric data that were collected in several EU-projects on sustainable supply chain management and green logistics.

An important observation in all three cases is related to the storage costs that are responsible for high percentages of the total costs. A closer view to the cost structure of all three options reveals that without the storage costs the order of the results would change, i.e. due to the high storage costs for LNG economic and ecologic advantages of certain distribution model for LNG are not able to emerge since they are superposed by the total high costs. This applies especially to the vessel - based distribution solutions that would be more favorable from the economic point of view in case of lower storage costs. Here, the technological development together with economy of scale effects in LNG - storage technology will have a positive impact on the cost structure of the LNG inventory routing problem so that ecologically better solutions are able to compete also economically with cheaper distribution forms.

Of special practical importance is the truck-to-ship bunkering of LNG that we discussed at the end of model B, which stores the LNG at the ports in additional truck equipment. This form of LNG bunkering is often used in ports since LNG terminals are still often missing even in larger ports. In our case such a truck-to-ship requires a larger truck fleet (in our case about 3 times larger) and also increases LNG supply costs (in our case ca. 10\%). Nevertheless, a truck-to-ship LNG bunkering solution leads to reasonable distribution costs per distributed ton of LNG in the ports but the truck-to-ship solution is rather something for a certain transition period as long as the LNG demand is low. In the long run, LNG terminals or LNG storing facilities are the safer and better solution for storing and handling larger volumes of maritime LNG demand so that we do not further discuss this solution here.

Consequently, in the current situation, the cheapest way is to use a distribution by trucks, as both the model using only vessels and the model using a mixture of truck and vessel supply are more expensive. Only if the storage price would fell dramatically the vessel model (model A) would be cheaper, as some ports do not have to be supplied at every time-step, which would also benefit the CO2emission of the vessel model, that is already lower than the emission of the truck model. Further, a supply by a mixture of vessel and trucks could be meaningful when considering costs as well as the ecological impact, as it is just a bit more expensive than the distribution using only trucks, but the caused CO2emissions are nearly half the size of the truck model.

A critical discussion about the results and its implications has to highlight the problem area of used prices for needed resources. In our calculations, we used daily prices in order to achieve a realistic picture of the underlying business situation. However, these actual figures only fully reflect the situation as a snapshot on the timeline that changes rapidly. Fuel price drops like in the first half of the year 2020 might lead to other conclusions than those we stated here. Nevertheless, a new economic reality can be calculated easily based on presented equation models. Finally, it has be mentioned that we neglected financial long-term aspects including an impact analysis if interest rates. All investments in our models contain long-term assets that are mainly covered by average values for depreciations and capital costs. A more sophisticated approach using methods from capital budgeting of real-option might deliver deeper results but also bears the risk of increasing the complexity of the models in such a way that the results do not longer reflect the economic reality. More research has to be done to develop the models further.

\section{Conclusion}

The research investigated on the estimated LNG-consumption in the German port at the Baltic and the North Sea and presented three different models on how these demands could be satisfied by vessels, trucks and a mixture of both, based on an IRP and a VRP formulation. After the introduction of the models, it was possible to obtain the costs for each supply mode for distribution and storage as well as to estimate the $\mathrm{CO} 2$ emissions of each scenario together with inter-arrival times between two LNG deliveries. All three LNG supply models revealed a high share of storage costs of the total costs so that the assessment leads different solutions under ecological and economic viewpoints. 
By summarizing the results, one can say that currently the main cost driver represents the storage of the LNG at each port and that the most economical way to master the costs is to reduce the amount of LNG stored at each port. For a transition period, until all ports are equipped with LNG terminal or sufficient stable LNG storages a truck-to-ship LNG bunkering represents a reasonable solution. Under the current conditions, an LNG-distribution by vessel in the North Sea and by truck in the Baltic Sea is economically comparable to the fully truck-based distribution.

The vessel - based distribution is from ecologic perspective the most favourable but is not able to compete in economic as well as in time dimension. Hence, the mixed vessel-truck distribution represents currently the most favourable LNG-supply mode for the German ports by taking under account all relevant dimensions of sustainable logistics. This outcome will only change in favour of the vessel-based model if the storage costs would drop dramatically.

\section{Acknowledgements}

The data collection of research work for this article has been supported by the European Regional Development Fund (INTERREG VB Baltic Sea Region programmes) in the frame of the EU-projects "GoLNG" and "EnviSuM".

\section{References}

1. Archetti, C., Bertazzi L., Laporte G., Speranza M. G. (2007) A Branch-and-Cut Algorithm for a Vendor-Managed Inventory-Routing Problem. Transportation Science, 41(3), 382-391, DOI: $10.1287 /$ trsc. 1060.0188 .

2. Atari, S., Bakkar, Y., Olaniyi, E.O., Prause, G. (2019) Real options analysis of abatement investments for sulphur emission control areas compliance. Journal of Entrepreneurship and Sustainability Issues, 6 (3), 1062-1086, DOI: 10.9770/jesi.2019.6.3(1).

3. Atari, S., Prause, G. (2018) Risk Assessment of Emission Abatement Technologies for Clean Shipping. Lecture Notes in Networks and Systems; 36, 93-101, Springer, Berlin, DOI: 10.1007/978-3319-74454-4-9.

4. Bektaş, T., Demir, E., Laporte G. (2016) Green Vehicle Routing. Green Transportation Logistics, 226, 243-265, Springer, DOI: 10.1007/978-3-319-17175-3_7.

5. Braekers, K., Ramaekers, K., Van Nieuwenhuyse, I. (2016) The vehicle routing problem: State of the art classification and review. Computers \& Industrial Engineering, 99, 300-313, DOI: 10.1016/j.cie.2015.12.007.

6. Bünger, U., Landinger, H., Weindorf, W., Wurster, R., Zerhusen, J., Zittel, W. (2016) Vergleich von CNG und LNG zum Einsatz in LKW im Fernverkehr. Retrieved from: http://www.lbst.de/ressources/docs2016/1605_CNG_LNG_Endbericht_public.pdf, accessed 05.03.2020.

7. Campbell, A. M., Savelsbergh M. W. P. (2004) A Decomposition Approach for the InventoryRouting Problem. Transportation Science, 38 (4), 488-502, DOI: 10.1287/trsc.1030.0054.

8. Cefic (2011) ECTA: Guidelines for Measuring and Managing CO2 Emission from Freight Transport Operations.

9. Cheng, C., Qi, M., Wang, X., Zhang, Y. (2016) Multi-period inventory routing problem under carbon emission regulations. International Journal of Production Economics, 182, 263-275, DOI: 10.1016/j.ijpe.2016.09.001.

10. Comité National Routier (2016) 2016 social synthesis of CNR's European studies. CNR Publications, Retrieved from: http:/www.cnr.fr/en/CNR-Publications/2016-social-synthesis-of-CNRs-European-studies, accessed 05.03.2020.

11. Daduna, J., Prause, G. (2017) The Baltic Sea as a maritime highway in inter-national multimodal transport, In: Doerner, K., Ljubic, I., Pflug, G., Tragler, G. (Eds.) (2015) Operations Research Proceedings 2015, 189-194, Springer-Verlag, DOI: 10.1007/978-3-319-42902-1.

12. Dantzig, G., Fulkerson, R., Johnson, S. (1954) Solution of a Large-Scale Traveling-Salesman Problem. Journal of the Operations Research Society of America, 2(4), 393-410, DOI: 10.1287/opre.2.4.393.

13. De, A., Kumar, S. K., Gunasekaran, A., Tiwari, M. K. (2017) Sustainable maritime inventory routing problem with time window constraints. Engineering Applications of Artificial Intelligence, 61, 77-95, DOI: 10.1016/j.engappai.2017.02.012.

14. Desrochers, M., Desrosiers, J., Solomon, M. (1992) A New Optimization Algorithm for the Vehicle Routing Problem with Time Windows. Operations Research, 40(2), 342-354, DOI: 10.1287/opre.40.2.342.

15. ECG (2020) Bunker Prices. The Association of European Vehicle Logistics, Retrieved from: http://ecgassociation.eu/Publications-Reports/General/Fuel-Prices/Bunker-Prices, accessed 06.03.2020. 
16. Enagás (2016) The LNG storage business and associated costs, Enagás Gas Assets General Management, Retrieved from: http://www.gainnprojects.eu/wp-content/uploads/2016/01/3.2.-TheLNG-Storage-Business-and-Associated-Costs-A\%CC\%81ngel-Rojo-ENAGA\%CC\%81S.pdf, accessed 05.03.2020.

17. Gendreau, M., Hertz, A., Laporte, G. (1994) A Tabu Search Heuristic for the Vehicle Routing Problem. Management Science, 40(10), 1276-1290, DOI: 10.1287/mnsc.40.10.1276.

18. Gleixner, A., Bastubbe, M., Eifler, L., Gally, T., Gamrath, G., Gottwald, R. L., Hendel, G., Hojny, C., Koch, T., Lübbecke, M. E., Maher, S. J., Miltenberger, M., Müller, B., Pfetsch, M. E., Puchert, C., Rehfeldt, D., Schlösser, F., Schubert, C., Serrano, F., Shinano, Y., Viernickel, J. M., Walter, M., Wegscheider, F., Witt, J. T., Witzig, J. (2018) The SCIP Optimization Suite 6.0. Optimization Online. Retrieved from: http://www.optimization-online.org/DB_HTML/2018/07/6692.html.

19. Hiermann, G., Puchinger, J., Ropke, S., Hartl, R. F. (2016) The Electric Fleet Size and Mix Vehicle Routing Problem with Time Windows and Recharging Stations. European Journal of Operational Research, 252(3), 995-1018, DOI: 10.1016/j.ejor.2016.01.038.

20. Kleywegt, A. J., Nori, V. S., Savelsbergh, M. W. P. (2002) The Stochastic Inventory Routing Problem with Direct Deliveries. Transportation Science, 36(1), 94-118, DOI: 10.1287/trsc.36.1.94.574.

21. Lalla-Ruiz, E., Expósito-Izquierdo, C., Taheripour, S., Voß, S. (2016) An improved formulation for the multi-depot open vehicle routing problem. OR Spectrum, 38(1), 175-187, DOI: 10.1007/s00291015-0408-9.

22. Laporte, G. (1992) The vehicle routing problem: An overview of exact and approximate algorithms. European Journal of Operational Research, 59(3), 345-358, DOI: 10.1016/0377-2217(92)90192-C.

23. LNG Density Calculator (2019). Retrieved from: https://www.unitrove.com/engineering/tools/gas/liquefied-natural-gas-density, accessed 05.03.2020.

24. MAN (2019) Propulsion of 7,000-10,000 dwt Small Tanker, MAN Diesel \& Turbo. Retrieved from: https://marine.man-es.com/docs/librariesprovider6/technical-papers/propulsion-of-7-000-10-000dwt-small-tanker.pdf?sfvrsn=16, accessed 05.03.2020.

25. MarineTraffic (2019) Retrieved from: https://www.marinetraffic.com/, accessed 21.01.2019.

26. MEG (2017). Potentialanalyse: LNG-Infrastruktur an der deutschen Nordseeküste unter Betrachtung besonders geeigneter Standorte, Merkel Energy GmbH. Retrieved from: https://www.ihkoldenburg.de/blob/olihk24/geschaeftsfelder/unsereregion/Infrastruktur/downloads/3876688/b2730ac8 bdcbfabd38805fcc714639ae/LNG-Studie-data.pdf, accessed 05.03.2020.

27. Morales, F., Franco, C., Mendez-Giraldo, G. (2018) Dynamic inventory routing problem: Policies considering network disruptions. International Journal of Industrial Engineering Computations, 523-534, DOI: 10.5267/j.ijiec.2017.11.001.

28. NOK (2020). Passagekosten Nord-Ostsee-Kanal. Retrieved from: http://www.kielkanal.de/html/passagekosten.html, accessed 05.03.2020.

29. Olaniyi, E.O., Atari, S., Prause, G. (2018) Maritime energy contracting for clean shipping. Transport and Telecommunication, 19(1), 31-44, DOI: 10.2478/ttj-2018-0004.

30. Olaniyi, E.O., Gerlitz, L. (2019) A LNG Maritime Energy Contracting Model. Entrepreneurship and Sustainability Issues, 7(1), forthcoming.

31. OpenStreetMap (2020) Retrieved from: https://www.openstreetmap.de/, accessed 12.02.2020.

32. Osman, I. H. (1993) Metastrategy simulated annealing and tabu search algorithms for the vehicle routing problem. Annals of Operations Research, 41(4), 421-451, DOI: 10.1007/BF02023004.

33. Otten, M., 't Hoen, M., den Boer, E. (2017) STREAM Freight Transport 2016. Retrieved from: https://www.cedelft.eu/publicatie/stream_freight transport_2016/1855, accessed 12.02.2020.

34. PBSL (2017) Analysis of Daily Vessel Costs, Pacific Basin Shipping Limited. Retrieved from: https:/www.pacificbasin.com/upload/en/ir/financial_disclosure/report/2017/IR/06\%20Analysis\%20o f\%20Daily\%20Vessel\%20Costs.pdf, accessed 05.03.2020.

35. Pochet, Y., Wolsey, L. (2006) Production Planning by Mixed Integer Programming. Springer Series in Operations Research and Financial Engineering, DOI: 10.1007/0-387-33477-7.

36. Prause, G. (2014a) A Green Corridor Balanced Scorecard. Transport and Telecommunication, 15(4), 299-307.10.2478/ttj-2014-0026.

37. Prause, G. (2014b) Sustainable Development of Logistics Clusters in Green Transport Corridors. Journal of Security and Sustainability Issues, 4(1), 59-68. DOI: 10.9770/jssi.2014.4.1(5).

38. Prause, G., Olaniyi, E. O. (2019) A compliance cost analysis of the SECA regulation in the Baltic Sea. Entrepreneurship and Sustainability Issues, 6(4), 1907-1921, DOI: 10.9770/jesi.2019.6.4(26).

39. Sea-distances (2019). Retrieved from: https://sea-distances.org, accessed at 12.02.2020.

40. Soysal, M. (2016) Closed-loop Inventory Routing Problem for returnable transport items. Transportation Research Part D: Transport and Environment, 48, 31-45, DOI: 10.1016/j.trd.2016.07.001. 
41. Soysal, M., Bloemhof-Ruwaard, J.M., Haijema, R., van der Vorst, J. G. A. J. (2018) Modeling a green inventory routing problem for perishable products with horizontal collaboration. Computers \& Operations Research, 89, 168-182, DOI: 10.1016/j.cor.2016.02.003.

42. Staffell, I. (2011) The Energy and Fuel Data Sheet. Retrieved from: https://www.clavertonenergy.com/wordpress/wp-content/uploads/2012/08/the_energy_and_fuel_data_sheet1.pdf, accessed 12.02.2020.

43. Stopford, M. (2009) Maritime Economics, 3rd edition, Routledge.

44. Van Anholt, R. G., Coelho, L. C., Laporte G., Vis I. F. A. (2016) An Inventory-Routing Problem with Pickups and Deliveries Arising in the Replenishment of Automated Teller Machines. Transportation Science, 50(3), 1077-1091, DOI: 10.1287/trsc.2015.0637. 